\title{
Anaesthetic approach to epidural hematoma, after minor head trauma, in an infant with previously unknown fibrinogen deficiency
}

\author{
Spartinou A., Chaniotaki F., Christofaki M., Arkalaki E., Astyrakaki E., Papaioannou A.
}

General University Hospital of Heraklion, Dept of Anaesthesiology, Heraklion, Greece

\section{Introduction}

Congenital fibrinogen deficiency is a rare autosomal disorder of coagulation with unknown prevelance and diverse range of bleeding phenotypes. Only few cases of CNS bleeding in paediatric patients with fibrinogen deficiency are reported and are related with increased morbidity and mortality. The perioperative management of an infant with an acute epidural hematoma after minor head injury, with previous unknown congenital fibrinogen deficiency, is presented.

\section{Case Report}

A previously healthy 10 months old infant $(11.7 \mathrm{~kg})$ was admitted to the emergency department after minor head trauma followed by vomiting episodes. The infant became lethargic and anisocoria was observed. Emergency brain CT revealed an epidural hematoma and the infant was transferred to the operating theatre for emergency craniotomy. The vital signs were HR 200/min, BP $85 / 38 \mathrm{mmHg}, \mathrm{SpO} 2100 \%$ and he was reacting only to painful stimulus. General anesthesia was induced and arterial and central venous catheter were inserted.

Preoperative $\mathrm{Hb}=7.8 \mathrm{~g} / \mathrm{dl}, \quad \mathrm{PLT}=271.000 \quad$ and coagulation tests were normal ( $\mathrm{INR}=1.33$, APTT $=26,8$ $\mathrm{sec})$. Major blood loss $(>250 \mathrm{ml})$ was recorded and resuscitation with $500 \mathrm{ml}$ crystalloids, $250 \mathrm{ml}$ of RBCs, $200 \mathrm{ml}$ of FFP and vasopressors was performed. Perioperatively new blood tests were ordered and arterial blood gases were repetitively assessed. At the end of operation another $50 \mathrm{ml}$ of blood were removed by the drainage resulting in severe hypotension. Despite the infusion of noradrenaline, bolus of adrenaline $(100 \mathrm{mcg})$, crystalloids and $120 \mathrm{ml}$ RBCs were needed for haemodynamic stabilization.

Transfer of the patient to the PICU was decided. During discussion with the family about the major blood loss, the mother reported for the first time positive family history of fibrinogen deficiency. The results of previously obtained blood tests revealed fibrinogen $=13 \mathrm{mg} / \mathrm{dl}$, $\mathrm{Hct}=18.2 \%, \mathrm{Hgb}=6,2 \mathrm{~g} / \mathrm{dl}, \mathrm{PLT}=110.000$ and INR 2.36, APTT $>120 \mathrm{sec}$. Therapy with fibrinogen concentrates was promptly initiated. During the stay in the PICU the patient suffered from epileptic seizures requiring treatment with anti-epileptic medication. The rest of the stay remained uncomplicated, and the infant was discharged without neurological injury.

\section{Discussion}

Fibrinogen has a key role in primary and secondary haemostasis and it is the first coagulation agent that is affected during haemorrhage ${ }^{1}$. Normal plasma fibrinogen level is approximately $200-450 \mathrm{mg} / \mathrm{dl}$.

Congenital fibrinogen deficiencies are either quantitative (afibrinogenemia-hypofibrinogenemia) or qualitative (dysfibrinogenemia). The afibrinogenemia incidence is estimated at 1:1.000.000, while the incidence of hypofibrinogenemia and dysfibrinogenemia is unknown and probably underdiagnosed. There is no consistent clinical presentation. The patient can experience bleeding episodes of varying severity or might be asymptomatic ${ }^{2,3}$.

The treatment depends on the severity of bleeding tendency. Antifibrinolytic amino acids (e.g. tranexamic acid) may be used for less severe forms of haemorrhages. In major blood loss episode, administration of fibrinogen concentrates is the treatment of choice. Suggested dose(g) $=$ desired increment in $\mathrm{g} \mathrm{L}^{-1} \mathrm{x}$ plasma volume. Fresh frozen plasma and cryoprecipitate may be an alternative treatment. For major surgery, a fibrinogen level $>100 \mathrm{mg} / \mathrm{dl}$ is recommended until healing is completed ${ }^{2}$.

Base excess in arterial blood gases was $<-6 \mathrm{mEq} / \mathrm{L}$, which is related with hypofibrinogenemia during haemorrhage. However, in the reported case decision was made not to administer fibrinogen concentrates before measurement of fibrinogen plasma level due to lack of experience in fibrinogen concentrates use in infants. Therefore we opted for FFPs instead ${ }^{4}$.

\section{Conclusion}

Congenital fibrinogen deficiency:

- May result in life threatening hemorrhage

- Base excess < $-6 \mathrm{mEq} / \mathrm{L}$ indicates hypofibrinogenemia during hemorrhage

- Fibrinogen concentrate is the treatment of choice

- Fibrinogen $\operatorname{dose}(\mathrm{g})=$ desired increment in $\mathrm{g} \mathrm{L}^{-1} \mathrm{x}$ plasma volume

\section{References}

Goobie SM Perioperative bleeding management in pediatric patients. Curr Opin Anaesthesiol. 2016 Jun;29(3):352-8

2. Bolton-Maggs PH The rare coagulation disorders--review with guidelines for management from the United Kingdom Haemophilia Centre Doctors' Organisation. Haemophilia. 2004 Sep;10(5):593-628

Peyvandi F Epidemiology and treatment of congenital fibrinogen deficiency. Thromb Res. 2012 Dec;130 Suppl 2:S7-11

4. Maegele M Hemotherapy algorithm for the management of trauma-induced coagulopathy: the German and European perspective. Curr Opin Anaesthesiol. 2017 Apr;30(2):257-264 